\title{
COMMENTARY
}

\section{Neuromuscular disease and extubation dysphagia}

\author{
David G Smithard*1,2 \\ See related research by Macht et al., http://ccforum.com/content/17/3/R119
}

\begin{abstract}
Post-extubation dysphagia is a common and serious problem. The presence of neuromuscular disease at the time of intubation is likely to increase this. Until recently, the prevalence and the association with length of intubation had not been clarified. Results published in this journal suggest that $93 \%$ of extubated patients with neuromuscular disease had post-extubation dysphagia, which in 33\% of cases was considered severe. The number of days ventilated was the single predictor of severe dysphagia and a consequent prolonged hospital stay. Further work to build on these results to unravel the complex interplay between disease, trauma, and other unknown factors will be required.
\end{abstract}

\section{Introduction}

Nutrition (that is, eating food) is not only a prerequisite for survival; it is also a frequently enjoyable and social function. As a consequence, when the ability to swallow is impaired (dysphagia), the ability to enjoy one's food both physically and socially is reduced.

People with neuromuscular disease may develop acute respiratory failure and be admitted to critical care for mechanical ventilation. Studies conducted in this area are frequently small and retrospective in nature. The article by Macht and colleagues [1] in a previous issue of Critical Care throws more light on this area of clinical uncertainty and begins to answer some questions and at the same time opens up further avenues for exploration.

\section{Discussion}

The presence of dysphagia is frequently under-recognized and suboptimally managed, especially in patients discharged from critical care back to a medical or surgical ward following extubation. In a retrospective study of

\footnotetext{
*Correspondence: david.smithard@nhs.net

'Department of Clinical Neurosciences, Institute of Psychiatry, King's College

London, 16 De Crespigny Park, London SE5 8AF, UK

Full list of author information is available at the end of the article
}

patients with acute respiratory failure and pre-existing neuromuscular disease, Macht and colleagues [1] reported that $93 \%$ of those patients discharged from critical care following extubation and transferred to a surgical or medical ward had post-extubation dysphagia, which in $33 \%$ of cases was considered severe. Of those with moderate or severe dysphagia, $66 \%$ were discharged from the hospital with dysphagia still present. In a similar cohort, without pre-existing neuromuscular disease [2], $84 \%$ had dysphagia, and only $17 \%$ were assessed as being severe. In both cohorts, those patients with dysphagia had a prolonged length of hospital stay and increased morbidity; mortality was not increased in the recent study.

As in many retrospective studies, only a minority of all the patients admitted and mechanically ventilated on critical care were included; $9 \%$ in the neuromuscular group and $25 \%$ in the non-neurological group were included in the studies $[1,2]$. This is a recurring problem with many studies in this area; the numbers are small, raising questions about generalizability of results $[3,4]$.

Many questions still require an answer. What is the true incidence of post-extubation dysphagia? Could the number with severe dysphagia be higher than suggested, as many patients did not undergo a Bedside Swallow Examination (BSE). How common is aspiration, silent or otherwise? In a small cohort of 35 patients studied by Tolep and colleagues [3], 16 had neuromuscular disorders; of these 16, 14 had an abnormal videofluoroscopy (VF) (modified barium swallow); and of these 14, 4 were aspirating. Leder [4], using fiberoptic endoscopic evaluation of swallowing (FEES), noted that 17 out of 52 patients aspirated, the majority silently.

Aspiration pneumonia is the most common form of hospital-acquired pneumonia and carries a mortality of $20 \%$ to $65 \%$ [5]. The development of complications, including pneumonia, following aspiration is dependent on many factors, including the physiological condition of the patient, and by definition many of these patients are at the limits of their physiological reserve [6], the frequency of aspiration, the contents of the aspirate and the quality of mouth care.

Macht and colleagues [1] are concerned that the BSE will not detect silent aspiration, and this is true by 
definition, but does that matter? We all aspirate, particularly at night when the frequency of swallowing is greatly reduced or ceases. The literature concerning silent aspiration following stroke is mixed. Many studies investigate preselected patients [7], who have been referred for assessment, whereas those studies investigating unselected patients do not find any particular association with aspiration [8]. Silent aspiration is detected only by instrumentation (VF/FEES) and, when detected in this way, appears to have no clinically apparent affect [4] and this would not be logistically practical in all patients and should be reserved for those patients who are most at risk of infection or continually develop chest infections or desaturation.

Why was pneumonia not associated more frequently with severe dysphagia? This cohort of patients with neuromuscular disease was a heterogeneous population, and how optimal was the management of the dysphagia (as good clinical management can reduce pulmonary complications [9]), or was mouth care very diligent to prevent aspiration pneumonia secondary to infected saliva?

The etiology of post-extubation dysphagia is likely to have multiple factors, including progression of the underlying neuromuscular disease critical care syndrome and trauma to the airway and muscle wasting/weakness. It is possible that this study by Macht and colleagues [1] missed significant variation in the occurrence of dysphagia because of the heterogeneity of the cohort or because the subgroups were too small for separate analysis.

Post-extubation dysphagia is a common and serious problem. Therefore, future studies in critical care populations should be undertaken prospectively and need to be adequately powered to detect clinically significant differences, and determine predefined subgroups must be identified for analysis. The data collected need to explore all possible etiology factors, including trauma due to a difficult intubation (1.5\% to $8.5 \%$ of intubation are classed as difficult [10]), and answer questions such as these: was pre-intubation dysphagia that had not been clinically apparent present, and what was the functional ability of the patient prior to intubation?

\section{Conclusions}

This study has begun to answer some of the questions around the complex problem of post-extubation dysphagia in neuromuscular disease. This should spur others on to further elucidate the relationship between extubation dysphagia, neuromuscular disease, and acute respiratory failure.

\section{Abbreviations}

BSE, Bedside Swallow Examination; FEES, fiberoptic endoscopic evaluation of swallowing; VF, videofluoroscopy.

\section{Competing interests}

The author declares that he has no competing interests.

\section{Author details}

'Department of Clinical Neurosciences, Institute of Psychiatry, King's College London, 16 De Crespigny Park, London SE5 8AF, UK. ${ }^{2}$ Kent Community Health NHS Trust, Upper Pemberton, Ashford, Kent TN24 4AZ, UK.

Published: 8 October 2013

\section{References}

1. Macht M, King CJ, Wimbish T, Clark BJ, Benson AB, Burnham EL, Williams A, Moss M: Post-extubation dysphagia is associated with longer hospitalization in survivors of critical illness with neurological impairment. Crit Care 2013, 17:R119.

2. Macht M, Wimbish T, Clark BJ, Benson AB, Burnham EL, Williams A, Moss M: Postextubation dysphagia is persistent and associated with poor outcomes in survivors of critical illness. Crit Care 2011, 15:R231.

3. Tolep K, Getch CL, Criner GJ: Swallowing dysfunction in patients receiving prolonged mechanical ventilation. Chest 1996, 109:167-172.

4. Leder SB: Incidence and type of aspiration in acute care patients requiring mechanical ventilation via a new tracheotomy. Chest 2002, 122:1721-1726.

5. Smith CA, Goldstein LB: Cough and aspiration of food and liquids due to oral-pharyngeal dysphagia. Chest 2006, 129:154S-168S.

6. Review of Clinical Guideline (CG83) - Rehabilitation after critical illness. London: National Institute for Health and Clinical Excellence; 2009.

7. Schmidt J, Holas M, Halvorson K, Reding M: Videofluorscopy evidence of aspiration predicts pneumonia and death but not dehydration following stroke. Dysphagia 1994, 9:7-11.

8. Smithard DG, O'Neill PA, Parks C, Morris J: Complications and outcome after acute stroke: Does dysphagia matter? Stroke 1998, 27:1200-1204.

9. Odderson IR, Keaton JC, McKenna BS: Sallow management in patients on an acute stroke pathway: quality is cost effective. Arch Phys Med Rehabil 1995, 76:1130-1133.

10. Lavery GG, McCloskey BV: The difficult airway in adult critical care. Crit Care Med 2008, 7:2163-2173.

doi:10.1186/cc12762

Cite this article as: Smithard DG: Neuromuscular disease and extubation dysphagia. Critical Care 2013, 17:194. 